\title{
PODER Y APARIENCIA: LA REVALORACIÓN DEL ARTE DEL GRABADO EN EL SIGLO XVIII Y SU REFLEJO EN LA EFIGIE DEL GRABADOR
}

\author{
Marina Gacto SÁnChez
}

Universidad Católica de Murcia

RESUMEN: En el presente trabajo reflexionamos sobre los retratos de artistas que trabajaron en el siglo XVIII y están presentes en la colección Iconografía Hispana. ${ }^{1}$ La selección de obras se enmarca en el deseo de estudiar la profesión de grabador y la influencia que los cambios socioculturales de este periodo cronológico tuvieron en la revalorización de su imagen. Se traza un análisis de las bases de su labor, su consideración social y la estimación de su figura pública estableciendo un balance final sobre estas cuestiones, teniendo como punto de referencia el análisis de la reflexión teórica que ha servido de cimiento para su representación.

Palabras clave: retrato, grabador, academia, autoridad, estatus.

ABSTRACT: Throughout this study we reflect on the portraits of artists that worked in the eighteenth century and are present in the Iconografia Hispana collection. The selection of works is delimited by the desire of revising the engravers occupation and how the socio-cultural changes occurring in this particular chronological period influenced its effigy. We analyze the foundations of their labour, social consideration and public figure appreciation. We also establish a final assessment on these issues taking as reference the theoretical reflection serving to the artist as a base for its representation.

1. Iconografía Hispana: catálogo de los retratos de personajes españoles de la Biblioteca Nacional. Esta obra se extiende en seis volúmenes editados entre 1966 y 1970 por la Sección de Estampas de la Biblioteca Nacional de Madrid, bajo la dirección de Elena Páez. Compuesta por unos 4500 retratos de personajes españoles de los siglos XV a XIX que se encuentran en los fondos de la Biblioteca Nacional, la mayoría son retratos grabados, ya sea en láminas independientes o en libros impresos. Véase ElENA PÁEz: «Los fondos del servicio de dibujos y grabados de la Biblioteca Nacional de Madrid», Boletín de ANABAD, 1992, vol. 42, n. ${ }^{\circ} 1$, pp. $117-151$. 
Keywords: portrait, engraver, academy, authority, status.

\section{El APOGEO DEL GRABADO EN EL SIGLO XVIII}

$\mathrm{F}^{\mathrm{l}}$ arte del grabado experimenta un gran auge en el siglo xviII y tal Eflorecimiento tiene su reflejo en la imagen del grabador, que se muestra haciendo gala del nuevo estatus alcanzado. El punto de inflexión sobre la valoración social de los grabadores parece producirse tras el cambio dinástico, configurándose claramente en la segunda mitad de siglo. Durante las primeras cinco décadas se consideran como meros artesanos al servicio de la devoción religiosa o de necesidades editoriales, entregándose mayoritariamente a la labor de incorporar algunas ilustraciones a los textos que ellos mismos editaban.

Su oficio y formación fue de poca relevancia hasta bien entrado el siglo xVIII, pero dicha situación cambió gracias al establecimiento de la enseñanza oficial de esta disciplina por parte de las academias. A pesar de esto, en la asamblea preparatoria de 1744-1752 y en los estatutos de 1751 no se menciona a los profesores de este arte. El 23 de junio de 1753 la Junta de la Academia acordó presentar al rey «que era evidente la necesidad de promover el estudio de este Arte», y en dicha sesión se solicitaba la creación de seis plazas para jóvenes que no tenían posibilidades económicas. El Estado convocó tres plazas para el grabado a buril y otras tres para el grabado en hueco. De entre los opositores, las plazas de grabado a buril quedaron bajo la dirección del maestro grabador Juan Bernabé Palomino. ${ }^{2}$

Para encontrar la primera mención relevante sobre profesores de este arte en el seno de la Academia, habrá que esperar a la distribución de los premios de 1754, donde ya se menciona que «desde el establecimiento de la Academia se tuvo por preciso procurar los adelantamientos del Arte del Grabado, tanto en el uso del buril y agua fuerte como en la formación de sellos, cuños y demás especies; así, para la más fácil propagación de las producciones de las tres artes, como otros innumerables fines». Desde el 12 de abril de 1752, fecha de la creación oficial de la Academia, se nombró a Tomás Francisco Prieto como grabador de medallas, y al citado Juan Bernabé Palomino como grabador en dulce y de cámara del rey. Un síntoma de la precaria situación de la actividad del grabador y de su pequeño número, así como de la escasa importancia que

2. Estatutos de la Real Academia de Bellas Artes de San Fernando [y aprobación real de los mismos], 1757, Gabriel Rodríguez, Biblioteca Academia Bellas Artes de Madrid, signatura C-1086 y B-1059. Véase en José EnRique García Melero: Literatura española sobre artes plásticas: bibliografía impresa en España entre los siglos XVI y XVIII, Ediciones Encuentro, Madrid, 2001 y CLAUDE BEDAT: La Real Academia de Bellas Artes de San Fernando (1744-1808), Fundación Universitaria Española, Madrid, 1989. 
se le concedía, es su carencia de organización gremial hasta bien entrado el siglo XVIII. El grabado calcográfico original, es decir, aquel que no reproduce imágenes y es una obra completa en sí misma, tuvo un escaso desarrollo en España.

Los nuevos estatutos de 1757 ya contemplan la enseñanza del grabado, de la que se encargarán los dos directores anteriormente mencionados. En este mismo año la Academia puede escribir con orgullo que los progresos realizados en el utilísimo arte del grabado son ya notorios aunque, sin embargo, se estima «muy conveniente añadir nuevos estímulos proponiendo a sus profesores un premio extraordinario, para darlo al mismo tiempo que se reparten los ordinarios de las tres Nobles Artes». ${ }^{3}$

El año 1792 será decisivo para la enseñanza del grabado en la Academia; se nombra entonces viceprotector a Bernardo de Iriarte y se reorganizan los estudios. Para la reforma de la enseñanza del grabado, Manuel Salvador Carmona redactó un informe que dio a conocer en la Junta especificando que sus alumnos copiaban estampas de Gerard Audran y de Antoine Masson, que habían adquirido gran admiración por la delicadeza de su buril. Para Salvador Carmona la actividad fundamental era copiar las obras de los grandes grabadores hasta adquirir un nivel adecuado y, en consecuencia, aconseja que los grabadores lean y trabajen la obra de Manuel de Rueda sobre la técnica del grabado. A pesar de estos avances, hasta finales del siglo xix la cátedra de grabado en nuestro país estará en manos de grabadores de reproducción, por lo que puede resultar comprensible la poca estima que por entonces se prestaba a este arte. ${ }^{4}$

\section{Los grabadores de la Real Cámara ${ }^{5}$}

El vehemente deseo de los grabadores de llegar a ser considerados como artistas de las bellas artes no alcanzó su realización hasta 1820. Según reglamento previo, la costumbre para la nominación de este cargo «ha sido siempre de la libre voluntad de S. M.».

El primer grabador de cámara de los Borbones fue Juan Bernabé Palomino en 1719, aunque no recibiría tal plaza hasta noviembre de 1736. En su caso, fue un puesto sin sueldo hasta que, en 1738, se le concedieron 400 ducados anuales; así, lo que se suponía un título honorifico, concedido como premio y estímulo, se convirtió en diversas ocasiones en un «castigo».

3. Juan Carrete Parrondo y Fernando Checa Cremades: El grabado en España; siglos xV al XViII, Summa Artis, Espasa Calpe, Madrid, 1988, p. 441.

4. Juan Carrete Parrondo: El grabado calcográfico en la España Ilustrada, Club Urbis, Madrid, 1978.

5. Analizaremos este tema ciñéndonos al grabado calcográfico puesto que se trata de la técnica comúnmente utilizada por los grabadores del siglo XVIII. 
Carlos José Flipart fue el único que, según Ceán Bermúdez, ostentó los títulos de pintor y grabador de cámara en 1750 . No obstante, parece que el título de grabador no fue efectivo, pues oficialmente la plaza se consideró vacante desde la muerte de Palomino en 1777 hasta el nombramiento de Manuel Salvador Carmona en 1783. A este respecto, Floridablanca dice:

En premio de la habilidad de don Manuel Salvador Carmona, director del grabado dulce de la Real Academia de San Fernando, y teniendo consideración al crédito que con sus obras ha adquirido de ser uno de los primeros grabadores de Europa, le ha nombrado S. M. por su Grabador de Cámara, cuya plaza ha estado vacante desde que murió don Antonio (por Juan Bernabé Palomino) con 8.000 reales de sueldo, debiéndole cesar la pensión de 6.000 reales que se le conservó y ha gozado desde que volvió de París, donde estuvo pensionado. ${ }^{6}$

En 1801, cuando ya hay un total de seis grabadores de cámara, Carmona se considera con derecho a ostentar la distinción de ser titular por ser el más antiguo, a semejanza de los pintores, es decir, ostentar el cargo de primer grabador de cámara. Pero la pretensión tiene un resultado negativo. A pesar del fracaso, Carmona firmó en tres ocasiones las láminas como primer grabador de cámara. ${ }^{7}$

En cambio, Fernando Selma, sin haberlo solicitado, fue nombrado grabador de la Real Cámara en 1799. La actitud de este artista durante el gobierno de Jose I fue claramente no colaboracionista, por lo cual murió sin haber publicado sus principales obras.

Si hasta entonces el nombramiento de grabadores de cámara se había producido de forma espaciada (cinco en sesenta y cinco años), a partir de 1801 el título se incrementa nombrando tres nuevos. En 1808 la lista aumentó considerablemente para incluir, entre otros, a José Assensio y Torres, Juan Moreno Tejada, Rafael Esteve y Vilella, Tomás López Enguídanos y Perles o Vicente Mariani y Todolí. Por otra parte, Blas Ametller, que había sido discípulo de Manuel Salvador Carmona, también solicitó ser nombrado grabador de cámara en 1814 y fue nombrado como tal en 1815.

Felipe Cardano Bauzá redactó en 1816 un proyecto para la creación de una escuela de grabado, puesto que la Academia de San Fernando no contaba con profesores. Nada de lo ideado se realizó. Una nueva técnica, la litografía, se introduciría en España y acapararía finalmente la protección real. Por tanto, el grabado en España gozó de poca fama, sobre todo si consideramos el escaso interés suscitado por nuestros artistas patrios en comparación con otros europeos. Habrá que esperar a Goya, y posteriormente a Picasso, para llegar al redescubrimiento de este arte en la Península.

6. Juan Carrete Parrondo y Fernando Checa Cremades, El grabado en España, p. 471.

7. José Luis Blanco Mozo, «La otra cara de la Ilustración. La formación Artística y la cultura del grabador Manuel Salvador Carmona a través del inventario de sus bienes », Anuario del Departamento de Historia y Teorías del Arte, Universidad Autónoma de Madrid, vols. 9-10, 1997-1998, pp. 277-312. 


\section{Literatura en torno al grabado}

El arte del grabado será revisado gracias al espíritu de la Ilustración y a sus círculos de eruditos. Los ilustrados reflexionarán sobre la historia del grabado en España y la importancia del artista grabador.

Nunca se promulgó legislación concreta alguna sobre esta profesión. Solamente, y ya en 1715, Antonio Palomino, en su libro El museo pictórico y escala óptica, equiparará el grabado a la pintura, considerándolo como arte liberal. Anteriormente, el propio García Hidalgo había tenido en su tratado palabras dedicadas a este arte. En esta época es cuando se construyen los primeros repertorios de artistas, en los que los grabadores tendrán un puesto importante, y cuando aparecen los primeros ensayos de literatura técnica en torno al grabado. ${ }^{8}$

El origen de la historiografía española sobre el grabado está sin duda en el Discurso histórico sobre el principio y progresos del grabado, de José de Vargas Ponce, leído en la Junta pública que celebró la Academia de San Fernando el 4 de agosto de 1790 y publicado en la distribución de premios de aquel mismo año. Aporta noticias sobre la historia del grabado de su tiempo, hace un primer balance de la situación del grabado ilustrado y presenta interesantes reflexiones sobre las causas de su escaso cultivo en España. ${ }^{9}$

En lo relativo a los repertorios de artistas, Ceán Bermúdez constituye la principal fuente de información de esta época a través de su Diccionario. En el último tomo introduce un apéndice, precedido por información sobre algunos artistas que no había incluido anteriormente en la obra, con tablas cronológicas y geográficas de los profesores españoles de las Bellas Artes divididos según las nueve artes del diseño. Así, se relacionan miniaturistas o iluminadores, escultores, pintores, plateros, vidrieros, relojeros, bordadores, y grabadores en dulce y en hueco, indicándose el lugar de su trabajo. Parece establecer dichas tablas según profesiones considerando la antigüedad y prestigio del oficio. Sitúa en primer lugar a los miniaturistas, posteriormente a los escultores y pintores, y cita por último a los grabadores. Menos conocido es el manuscrito anónimo titulado Noticias, documentos y papeles para formar un diccionario de pintores, escultores y grabadores, obra trabajada en esta corte por un apasionado de las bellas artes, Madrid, 1796, y digna de consulta aunque aporte pocas novedades. La Biografía pictórica valentina de Marcos Antonio de Orellana aporta también noticias acerca de la profesión, aunque circunscritas a artistas valencianos.

Manuel de Rueda, comisario extraordinario del Estado Mayor para la Real Artillería, estampó en 1761 un escrito titulado Instrucción para grabar en cobre y perfeccionarse en el grabado a buril, al aguafuerte y al humo, con un

8. Pilar Silva Maroto: «La influencia del grabado en el Arte de la época de Carlos III», El Arte en Tiempos de Carlos III. IV Jornadas de Arte, CSIC, Madrid, 1989, pp. 401-411.

9. Véase Antonio Gallego: Historia del grabado en España, Cátedra, Madrid, 1979, pp. 275-277. 
nuevo método de grabar las planchas para estampar en colores a imitación de la pintura, y con un compendio histórico de los más célebres grabadores que se han conocido desde su invención hasta el presente. El documento es realmente poco original, porque traduce tratados perfectamente conocidos, desde la obra del propio Bosse, el primero sobre técnicas calcográficas, a otras obras más modernas. A pesar de ello, este manual fue muy empleado en su tiempo y no superado ni tan siquiera en el siglo xix. Algunos grabadores lo completaron con técnicas nuevas, como la aguatinta o el grabado a la aguada, pero sin abordar un tratado general sobre la materia.

Juan Moreno de Tejada también fue continuador del espíritu didáctico de la Ilustración. Estudió el arte del grabado y se declaró autodidacta porque consideraba a Palomino demasiado antiguo y Carmona estaba entonces ausente en París. Fue autor de un poema en cuatro silvas titulado Excelencias del pincel y del buril, publicado en 1804. Dedicó la última silva al grabado, que llamó Pintura Monocromática. Conceptualmente, es probable que se inspirara en las Investigaciones filosóficas sobre la belleza Ideal escritas por Esteban de Arteaga.

EFIGIES DE PODER: GRABADORES DEL SIGLO XVIII

\section{Tomás Francisco Prieto}

Tomás Francisco Prieto nació en 1716 en Salamanca y falleció en 1782. Su hija María de Loreto también se dedicó al oficio del grabado siendo miembro honorario de la Academia de San Fernando. El nombre de esta familia quedará para siempre unido a la real institución, puesto que, representando la rama del grabado, Francisco Prieto fue uno de los primeros académicos que se reunieron en el verano de 1744 tras la aprobación real de los reglamentos preparatorios para su fundación. El 12 de abril de 1752, tras la promulgación del real decreto de la fundación de la Academia, fue designado director honorario de este arte como grabador de medallas, junto con Juan Bernabé Palomino, grabador en dulce y de cámara del rey,

La estampa que nos ocupa [Fig. 1] lleva por signatura IH/7470 en la Biblioteca Nacional y contiene el siguiente título: «Retrato de Tomás Francisco Prieto. Ignacia Bustamante, A su esposo amantísimo con quien vivió 16 años sin discordia...». El artista está representado en más de medio cuerpo y sostiene en la mano derecha una medalla y unas estampas, mientras su mano izquierda se apoya en una carpeta, quizás repleta de ilustraciones. Respecto al óleo que reproduce, Pérez Sánchez sugiere que podría haberlo realizado González Ruiz hacia 1766, teniendo en cuenta que el grabador parece representar unos 
cincuenta años y que viste a la moda de Carlos III con peluca corta. ${ }^{10} \mathrm{La}$ semejanza con el propio Autorretrato del artista, obra ejecutada hacia 1786 y conservada en la Real Academia de San Fernando, parece confirmar también la fecha aproximada. ${ }^{11}$

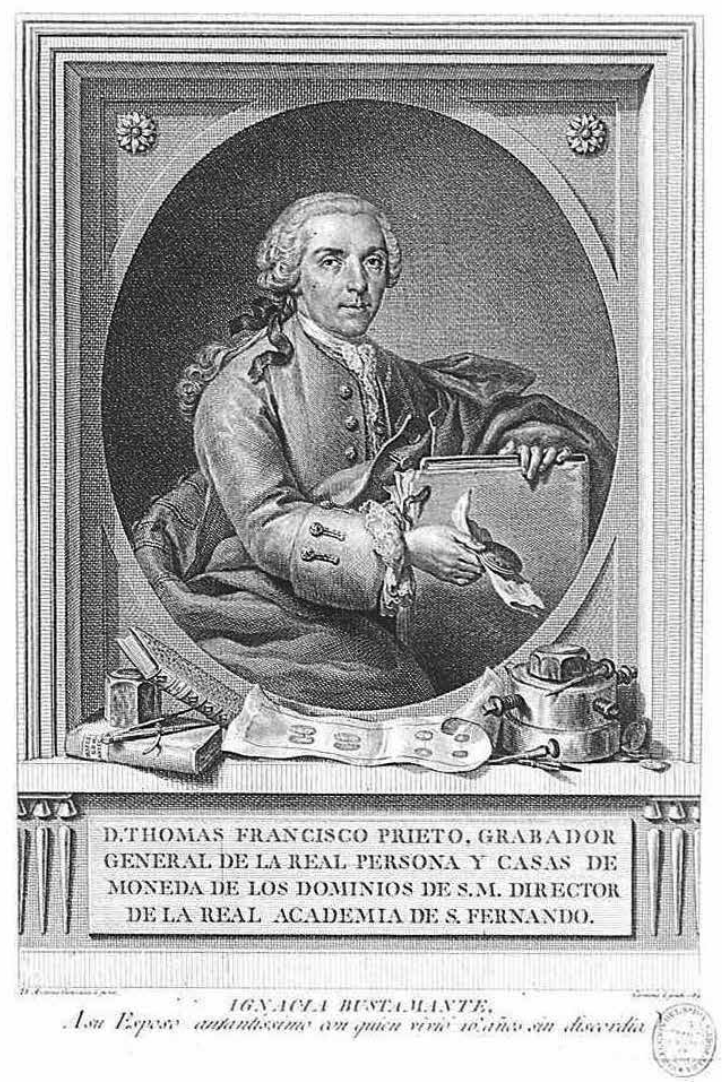

Fig. 1. IH/7470. Salvador Carmona, Manuel (1734-1820). Retrato de Tomás Francisco Prieto. Ignacia Bustamante, A su esposo amantísimo con quien vivió 16 años sin discordia. Descripción física: estampa; huella de la plancha $222 \times 305 \mathrm{~mm}$. Biblioteca Nacional de Madrid. Iconografía Hispana. Colección Carderera

10. Alfonso Emilio Pérez Sánchez: «Algunos retratos desconocidos de Antonio González Ruiz», Tiempo y espacio en el arte: homenaje al profesor Antonio Bonet Correa, Editorial Complutense, Madrid, 1994, p. 915.

11. José Luis De Arrese: Antonio González Ruiz, Instituto de Estudios Madrileños, Madrid, 1973, lám. 1. El retrato lo grabó en 1786 F. Muntaner, envejeciendo los rasgos y cambiando el peinado, pero respetando literalmente composición y gesto. 
Como en otras de sus obras, la pintura de González Ruiz en el género del retrato se caracteriza por un perfecto tratamiento de los trajes, centrando la atención en la ropa y sus pliegues. ${ }^{12}$ Añade a sus figuras una pose que resulta determinante, buscando la elegancia en las actitudes del retratado. El tratamiento es expresivo y el rostro, lleno de vitalidad, fue respetado en el grabado; pese a envejecer sus rasgos y cambiar el peinado, conservó el gesto y la composición. Se trata de un retrato íntimo que adquirió en la estampa una mayor opulencia formal, debido a la intención por parte del grabador Manuel Salvador Carmona de una exaltación honorífica pues, como indica la dedicatoria, se trataba de un homenaje de la esposa del retratado, Ignacia Bustamante. Lleva las inscripciones: «Don Antonio González le pintó», y «Carmona le grabó en 1784», es decir, dos años antes de producirse la muerte de Prieto. El grabador inscribe el retrato en un marco ovalado, de acuerdo con el gusto de la época. Los atributos del arte del grabado que acompañan al retrato tienen, en conjunto, una intención honorable puesto que como grabador general de medallas y de la Casa de la Moneda, mejoró y renovó a través de sus lecciones el grabado en España e Indias.

La figura de este grabador aparece unida a la propia imagen del rey. Gracias a sus labores como experimentado grabador al servicio de la corona, y a la unificación monetaria culminada por el rey Carlos III, veremos cómo en el siglo XVIII se produce la consolidación de una imagen única regida por la misma moneda. A ello contribuyó su difusión uniforme por todos los territorios de la corona fundando la idea de «la universalidad del poder del estado», donde la efigie real personificaba su control sobre todos los sectores de la actividad económica. Arte y poder que el experimentado grabador en el prestigioso arte de la medallística manifiesta en su propio retrato. El origen del museo de la Casa de la Moneda se remonta al estudio formado por Tomás Francisco Prieto, destinado a la formación de sus discípulos de la Escuela de Grabado creada en 1772 por el rey Carlos III, con el objetivo de formar grabadores oficiales para sus casas de monedas. ${ }^{13}$

En este contexto queremos también destacar la figura del ensayador de la Real Casa de la Moneda, Bernardo Muñoz de Amador, quien publicó en 1755 el Arte de ensayar oro, y plata, con breves reglas para la theorica, y la practica, defiendo el oficio, sus honras y favores, a quien Prieto grabó en un célebre retrato. ${ }^{14}$

12. Afirma que «consigue una vibración y elegancia en la calidad de las telas, de modo enteramente francés». Véase en Alfonso Emilio Pérez SÁnchez: Historia del dibujo en España desde la Edad Media a Goya, Cátedra, Madrid, 1986.

13. Reyes Durán González-Meneses: Catálogo de los dibujos de los siglos XVI y XVII de la colección del Museo de la Casa de la Moneda, Fábrica Nacional de Moneda y Timbre, Madrid, 1980.

14. Realizado bajo la inscripción «Situazion en la que Dn. Bernardo Mvñoz egecuta los en sayes de oro y plata - isu retrato» que hoy se encuentra en la Biblioteca Nacional de Madrid, IH/6328. 
Entre los discípulos de Prieto figuran grabadores como Pedro González de Sepúlveda, su yerno y digno sucesor, y don Antonio Espinosa. Otro de sus discípulos, el grabador Jerónimo Gil, ${ }^{15}$ no tuvo tanta suerte y viendo un porvenir sombrío a las órdenes de Prieto, que monopolizaba el grabado en hueco en la Península -y con quien había tenido un grave enfrentamiento por atreverse a criticar una de las medallas acuñadas por él- decidió finalmente marchar a México. Resulta notable que, como reza el informe ${ }^{16}$ remitido al ministro Múzquiz en el verano de 1769, Tomás Prieto fue acusado de favoritismo a la vez que se le reprochaba el celo con que impedía que sus alumnos lo adelantasen. Se adjuntaba al informe un proyecto de reglamentación para recortar los derechos privativos de su nombramiento como grabador general. En este hecho podemos apreciar cómo sus relaciones establecidas con otros miembros de la comunidad no siempre fueron ventajosas.

Por los datos antes mencionados sobre la creación y distribución del profesorado, podemos afirmar que González Ruiz y Francisco Prieto compartían lugar de trabajo e incluso amistad. ${ }^{17}$

Tomás Francisco Prieto trabajó con el grabador Carmona en la publicación de Antigüedades árabes en España desde 1756, obra de gran envergadura que se gestó en el seno de la Academia de Bellas Artes de San Fernando. Tras la fundación de la Academia en 1752, Luis Salvador Carmona también figuraba como docente en la institución, lo que permite deducir que ambos compartían así mismo espacio de trabajo, probablemente amistad e incluso un común deseo de enaltecer la profesión a través de su trabajo.

Antonio González Ruiz, autor secundario de la estampa, nació en Navarra en 1711, y fue nombrado en 1768 director general de la Real Academia. Como célebre retratista, merece la pena destacar el retrato realizado en 1741 a su suegro Juan Bernabé Palomino donde equilibra sus influencias francesas con el barroco hispano tradicional. En esta línea realiza su propio Autorretrato en 1768, conservado en la Academia de San Fernando, celebrando su nombramiento institucional. ${ }^{18}$ Con la difusión de estos grabados se dignificaba esta profesión en España a través del insigne retrato de Tomas Francisco Prieto, en calidad de grabador, artista y académico.

15. Creador de la Real Academia de San Carlos de Nueva España, aprobada su fundación por real orden el 25 de diciembre de 1778, a la que en 1784 se le otorgaron los estatutos de independencia total de la de Madrid. Véase a continuación.

16. Véase el informe escrito por el marqués de Monterreal, presidente de la Junta de Comercio y Moneda.

17. Esta afirmación viene de la mano de Ceán Bermúdez, único testimonio que he podido encontrar acerca de dicho grabado. En la biografía de Prieto, afirma que fue amigo «de nuestro D. Tomas, pintó su retrato de más de medio cuerpo, que grabó a buril el año de 1784 su compañero D. Manuel Salvador Carmona».

18. Esta obra fue grabada por su yerno Montañez. González Ruiz también realizó un retrato de su suegro Juan Bernabé Palomino en 1741, una pieza interesante para comprobar esas relaciones establecidas entre los diversos miembros de la profesión. 


\section{Jerónimo Antonio Gil}

Nacido en Zamora en 1732 fue uno de los primeros discípulos de la Academia de San Fernando, que pensionó sus estudios en Madrid bajo la dirección de Tomás Francisco Prieto. Destacan entre sus obras las medallas y monedas que grabó para la proclamación de Carlos IV y la copiosa colección de punzones y matrices de letras para la Biblioteca Real, siendo la más completa que se conoce en Europa. Tras la jubilación de Alejo Bernabé Madero fue enviado a la Casa de México a cubrir la plaza vacante, en calidad de grabador honorario para colaborar con Francisco Casanova. ${ }^{19}$ Como hemos mencionado, viendo su porvenir sombrío en España a las órdenes de Prieto, que monopolizaba el grabado en hueco en la Península y con quien había tenido un grave enfrentamiento, decidió marchar a México.

Así, tras abandonar España, Gil recibió el nombramiento de tallador principal de la Casa de la Moneda de México el 15 de marzo de 1778, con el encargo de establecer en aquella casa una escuela del grabado. ${ }^{20}$

Gil concibió la idea de fundar una escuela de dibujo donde los alumnos pudieran acudir en horario de noche; debido al enorme éxito de esta creación decidió establecer una escuela de Bellas Artes primero y después una academia a semejanza de las de San Fernando en Madrid y San Carlos en Valencia. Su creación fue aprobada por real orden el 25 de diciembre de 1778, y en 1784 se expidió el real despacho de fundación con el título de Real Academia de San Carlos de Nueva España, cuyos estatutos le otorgaban una total independencia de la de Madrid. Como director de grabado en hueco se nombró a Jerónimo Antonio Gil y para grabado en lámina se designó a José Joaquín Fabregat, tras la renuncia de Fernando Selma. ${ }^{21}$

La estampa que conservamos con la imagen de este artífice [Fig. 2] lleva por signatura IH/3747 en la Biblioteca Nacional y fue dibujada por Tomás Suria, su discípulo predilecto, nombrado tallador mayor a la muerte de Gil. Este retrato responde a la cordial relación que ambos mantenían. Los rasgos faciales de Gil quedan suavizados hasta una amabilidad casi compasiva.

Queda patente esta idealización si se compara esta obra con la realizada por Rafael Jimeno y Planes, pintor y grabador español que ocupó el cargo de director de la Academia de San Carlos de México y cuya gran aportación al arte mexicano fue la introducción de la corriente neoclásica. Jimeno realizó, en torno a 1780, un retrato de Gil que hoy se encuentra en el Museo Nacional

19. Esta plaza ocupada por Madero había sido anteriormente propuesta a Gil, que la había rechazado, pero que aceptó sin dudar la segunda vez decepcionado por haber sido rechazado para ocupar la plaza de director de grabado en dulce, vacante desde 1777, frente a Manuel Salvador Carmona.

20. La creación de la Escuela de Grabado de la Casa de la Moneda de Madrid se sitúa dentro del impulso que Carlos III dio a las industrias artísticas durante su reinado. Su propósito era completar la formación que los alumnos de la Academia recibían y proporcionar a los futuros grabadores de las casas de España e Indias la preparación teórica y artística necesaria para el grabado de monedas, medallas, sellos y firmas.

21. Es probable que no fuera realmente una renuncia, sino una decisión del rey, ya que este puesto resultaba atractivo para cualquier profesor. 


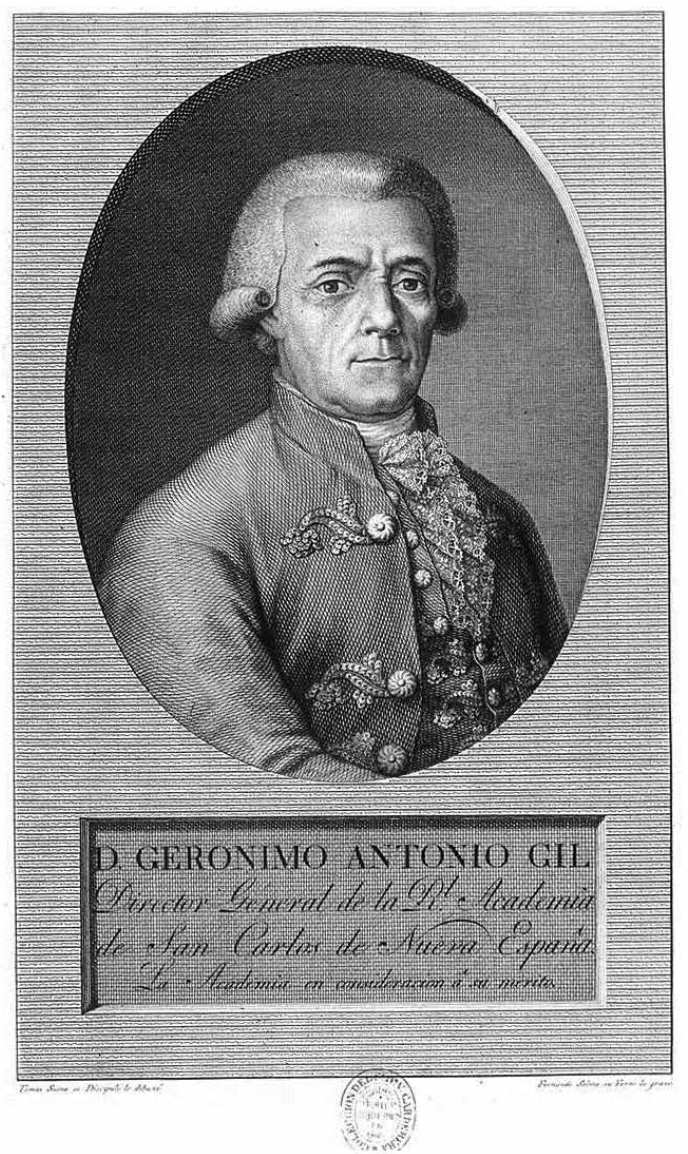

Fig. 2. IH/3747. Selma, Fernando (1752-1810). Retrato de Jerónimo Antonio Gil / Tomás Suria su Discipulo lo dibuxó; Fernando Selma su Yerno lo gravó. Descripción física: 1 estampa: grab. calc.; huella de la plancha $303 \times 211 \mathrm{~mm}$. Biblioteca Nacional de Madrid. Iconografía Hispana

de Arte en México D. F. Muestra a un artista con útiles en mano y una actitud seria, con gesto de superioridad. Suponemos, por la fecha de ejecución, que encargó esta imagen a su llegada al nuevo continente como símbolo de su poder y su talento frente a los colonos.

El retrato se inserta dentro de la producción grabada por Fernando Selma, claro exponente del dirigismo reformista que la Ilustración tuvo en España y a través del cual se intentaron fomentar los estudios de grabado. La obra de Selma resume en sí misma los ideales de la Ilustración. Natural de Valencia, nació en 1752 y estudió en la Academia de San Fernando teniendo como maestros a Carmona y a Bayeu. En 1783 fue nombrado académico de mérito 
de la Real Academia de San Fernando y director honorario de la de San Carlos. Más tarde empezaría a grabar su obra magna, Atlas marítimo de España, por la cual obtuvo el título de grabador de cámara. Su carácter dócil, apacible, y modesto le hicieron captar la amistad de cuantos le trataron. ${ }^{22}$ En 1782 contrajo nupcias con María Manuela Gil, hija de Gil, y es probable que este retrato fuera un encargo de la Academia de San Fernando a Gil como premio a sus logros en el campo del grabado. Por su parte. Agustín Esteve realizó un retrato del propio Selma que actualmente se conserva en el Museo Sant Pius V de Valencia ${ }^{23}$ y cuyo grabado forma parte de los fondos de Iconografía Hispana de la Biblioteca Nacional en Madrid bajo la signatura IH/8808. Se trata de una estampa de factura anónima cuya imagen viene inscrita en un óvalo, bajo el cual queda inscrito «D. Fernando Selma. Grabador de Cámara de S. M.».

\section{Mariano González Sepúlveda}

Hijo del grabador general Pedro González de Sepúlveda, ${ }^{24}$ nació en Madrid en 1774. Comenzó su carrera en la Escuela de Grabado de la Casa de Moneda como discípulo de su padre y desde el año 1785 trabajó en la Academia de San Fernando, entidad que en 1793 le concedió el único premio del grabado de medallas. En 1795 fue elegido académico de mérito por esta especialidad.

En 1797, a propuesta de Godoy, fue pensionado por el Gobierno para estudiar en París el nuevo método mecánico de acuñar monedas y medallas según el invento del grabador Jean-Pierre Droz, el arte de la estereotipia, para su posterior introducción en España. Debido a sus progresos junto al nuevo maestro fue nombrado segundo grabador de la Casa de la Moneda de España e Indias en 1801. Se desconocen las razones por las que no obtuvo a su regreso ningún éxito en este arte de multiplicar las láminas para los estampados. No obstante, José Bonaparte le confirmó para trabajar como ayudante de su padre en la Casa de la Moneda y más tarde este le refrendará el título de segundo grabador general.

Al regreso de Fernando VII fue desterrado a Barcelona, pero a falta de profesorado para la enseñanza del grabado fue de nuevo llamado a Madrid en 1820. Se le designó entonces director artístico del ramo de grabado y fundición de la Imprenta Real. Tres años después regresó a la Casa de Madrid como grabador general encargado de la dirección del Departamento de Grabado y Máquinas.

22. Es el grabador de quien más se han alabado sus cualidades humanas. Sin haberlo solicitado, en 1799 se le nombró grabador de la Real Cámara. La actitud del artista durante el gobierno de José I fue de no colaborar, por lo cual murió sin haber publicado sus principales obras.

23. Fernando Selma. El Grabado al servicio de la cultura ilustrada, cat. exp., Fundación la Caixa, Madrid-Valencia, 1993, no. 272 y 250.

24. Este a su vez había sido formado por su suegro, Tomás Francisco Prieto, profesor de la Academia entre 1752 y 1782 . 


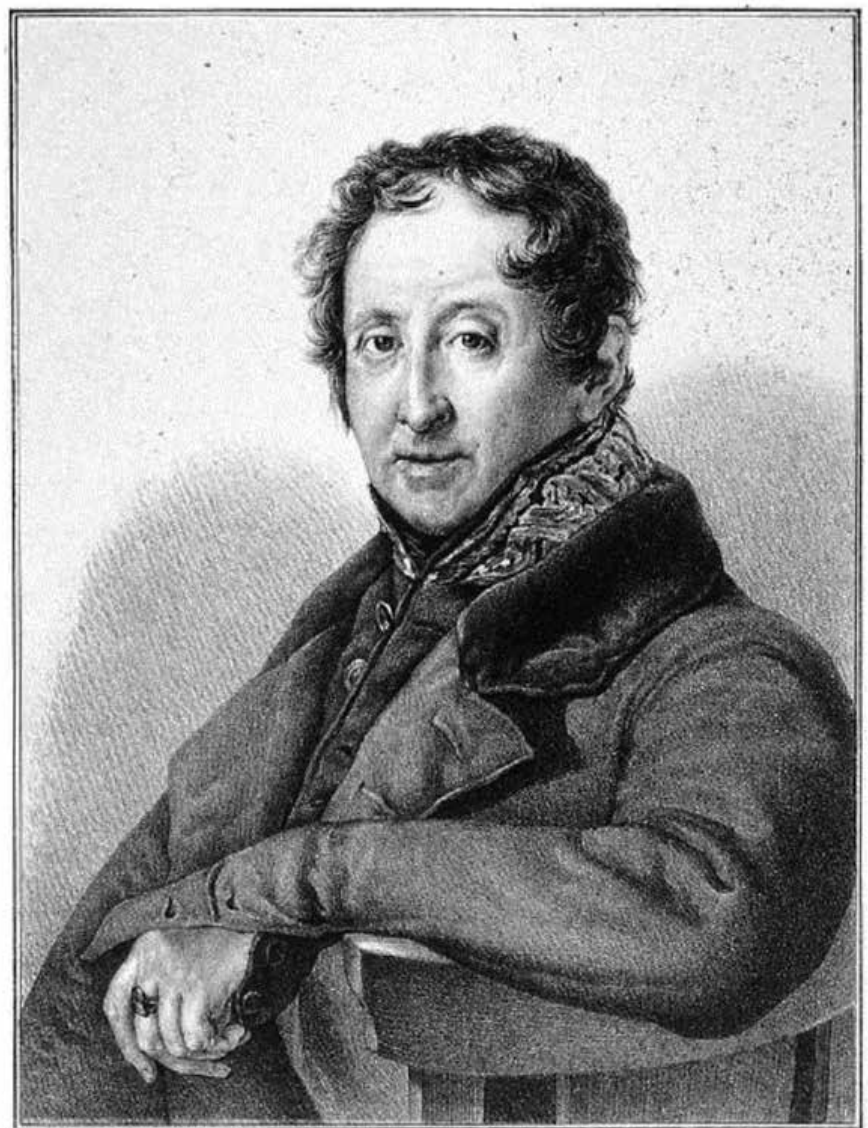

Fig, 3. IH/ 4013/1. López, JuAn Antonio. Retrato de Mariano González Sepúlveda / V. López, pinx; J. A. López Litog. Descripción física: 1 estampa, litografía; $160 \times 144$ mm, en h. de $308 \times 230$ mm. Biblioteca Nacional de Madrid. Iconografía Hispana

El grabado que aquí se presenta [Fig. 3] es copia de un retrato realizado por Vicente López en 1835 sobre la figura de Mariano González Sepúlveda. En el catálogo razonado de José Luis Díez se describe como el retrato de un personaje vistiendo levita con cuello de terciopelo bajo la cual asoma su uniforme de funcionario de palacio. ${ }^{25}$ Pocos datos tenemos sobre este grabado, pero sabemos que Vicente López compartía con Sepúlveda una estrecha amistad debido a sus respectivos trabajos en el ámbito cortesano.

25. José Luis DíEz: Vicente López. Catálogo razonado, Fundación de Apoyo a la Historia del Arte Hispánico, Madrid, vol. 2, 1999, n. ${ }^{\circ}$ 600, p. 147. 
Vicente López, primer pintor de cámara desde 1815, nos muestra al grabador con los rasgos faciales marcados; se trata de un retrato realista en el que por medio de la fisionomía nos expresa su aprecio por el retratado, confirmando esa supuesta amistad con el grabador madrileño. Esta obra, fechada hacia 1836, constituye una exaltación artística al representar el reconocimiento social y el estatus palaciego alcanzado por el protagonista, patente tanto en la actitud como en las vestiduras del personaje.

\section{Retrato de Rafael Esteve}

Nacido en Valencia a finales del siglo XVIII y nombrado grabador de cámara de Carlos IV ${ }^{26}$ se nos muestra en una soberbia representación que combina una representación íntima, con un sentimiento de admiración y respeto por parte del propio Francisco Goya. La fisionomía es aguda, de rasgos finos y mirada vivaz. Se trata de una efigie con un fuerte estudio psicológico que capta el temperamento concentrado y nervioso del retratado.

La posición de su cuerpo denota un deseo de notoriedad, doblando su brazo izquierdo mientras su mano derecha sostiene una plancha de grabado. Sobre la mesa hay unos papeles, que probablemente simbolizan el fruto artístico de su actividad. Una labor que le permite ser calificado como el primer grabador español hasta su época.

Camón Aznar hace referencia a la estima que Goya debía tener de este retrato, ya que realizó una cabeza preparatoria que hoy se encuentra en el Museo Lázaro Galdeano ${ }^{27}$ su factura es abocetada, pero desprende una intensa expresividad en sus rasgos físicos. Su reducido tamaño $(98 \times 75 \mathrm{~cm})$ y su fecha de ejecución, 1815, coincidiendo con su solicitud para ser nombrado académico de mérito de la Real Academia de San Carlos de Valencia, induce a pensar que se trata de un encargo privado que el grabador pudo haber recomendado a Goya para su ejecución. Acababa entonces de visitar Europa, y se le había concedido la plaza vacante por muerte de Tomás López Enguidanos, lo que indica que se hallaba en un momento profesional álgido y que necesitaba una imagen para poder resaltar su estatus.

La repercusión que este retrato tuvo es indudable, no solo por la gran cantidad de variantes que la Biblioteca Nacional nos ofrece en su fondo de grabados, sino porque la imagen que Goya nos presenta de Rafael Esteve fue extendida hasta el ámbito de la numismática en el siglo xix. Dentro de la Colección Iconografía Hispana encontramos varias estampas que reproducen

26. JosÉ RUIZ DE LIHORY (barón de Alcahalí) precisa en su biografía sobre Rafael Esteve que la portada para la Guía de Forasteros, con retratos de los reyes le hizo merecedor de este cargo en 1802. Véase en: Diccionario Biográfico de Artistas Valencianos, París-Valencia, Valencia, 1989, p. 109. Reproducción facsímil de la edición de Valencia, Imprenta de Federico Doménech, 1897.

27. José Camón Aznar: Francisco de Goya, Instituto Camón Aznar, Zaragoza, vol. 2, 1980, p. 39. 


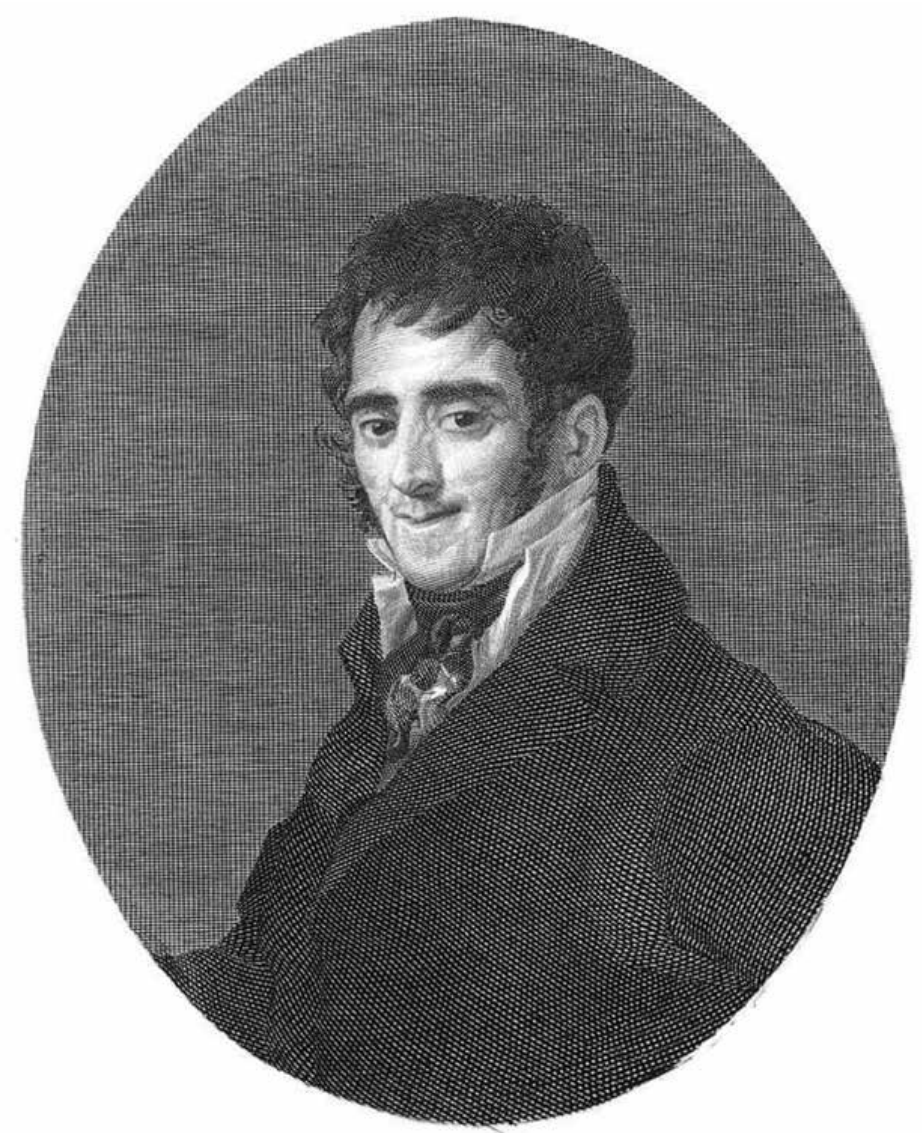

Fig. 4. IH/2895/1. Franch y Mira, Ricardo (1839-1888). Retrato de Rafael Esteve / Grabado en 1874 por Ricardo Franch y Mira para la oposición a la cátedra de grabado de la Escuela de Bellas Artes. Descripción física: 1 estampa: aguafuerte y buril. Huella de la plancha $262 \times 197 \mathrm{~mm}$ en h de $315 \times 223 \mathrm{~mm}$. Biblioteca Nacional de Madrid. Iconografía Hispana

esta obra. Entre ellas, destacamos la realizada por Ricardo Franch y Mira [Fig. 4] en 1874 que le permitió obtener la plaza de profesor de Grabado y Dibujo del Antiguo, estando vacante la cátedra de Grabado de la Academia de San Carlos. barón de Alcahalín ${ }^{28}$ cita esta obra, que actualmente se conserva en Biblioteca Nacional de Madrid con signatura IH/2895/1, entre sus trabajos más notables.

28. José Ruiz De Lihory (barón de Alcahali), Diccionario Biográfico de Artistas Valencianos, p. 125. 
Navarrete y Fosch, también realizó otra estampa que reproducía el cuadro de Goya. Profesor de grabado en la Escuela de Bellas Artes de Barcelona desde 1865, obtuvo una medalla honorífica en la Exposición Nacional de 1878 por esta obra, según noticias que nos proporciona Bernard Ossorio. ${ }^{29}$ Destacó en el género de la retratística y una de sus obras más celebres es el retrato que realizó de Iusepe Martínez para ilustrar sus Discursos Practicables del arte de la pintura, publicados por la Academia de San Fernando en 1866. Esta obra es significativa dentro de la producción artística de Navarrete no solo por lo que la efigie plástica pueda significar, sino por lo que la obra de Iusepe Martínez representa dentro del ascenso del estatus del artista en la historia del arte español.

\section{CONClusiones}

Mediante la selección de retratos de grabadores setecentistas que hemos abordado y el estudio de la evolución histórica de su arte en el marco cronológico abarcado, podemos concluir que, a través de su imagen, el representado intenta legitimar su creciente estatus social. En la mayoría de estos retratos encontramos esta autentificación no solo en el retratado, sino en el artista que lo retrata. Teniendo en cuenta que estas imágenes fueron efectuadas por artistas cercanos a los propios retratados, por relaciones profesionales o familiares, podemos comprobar que se trata de una sociedad igualitaria en la que el artista no tendrá que callar el afecto que sentía para sus retratados. Representan el resultado de una lucha por la democratización de la imagen, que llegará a su apogeo en el siglo xix.

Puede también constatarse que estos artífices se legitiman públicamente como seres con habilidades excepcionales. Todo este proceso llegará a su máxima expresión con la idea del genio romántico. Mientras tanto, el papel que la Academia de San Fernando juega en esta evolución es fundamental, pues propicia el cambio de estatus del creador plástico separando a los artistas de los artesanos. La fundación de la Real Academia de Bellas Artes de San Fernando también supuso un aumento de la producción artístico-literaria, ya que se constituyó como auténtico centro promotor de la cultura del momento.

Con la Ilustración se pretende una vuelta al racionalismo clasicista en las artes y se plantea de una manera especial la exigencia de la utilidad a cualquier actividad de carácter social. Este pensamiento afectó particularmente a la Academia, que abrió el debate teórico sobre la utilidad social de las nobles artes y ofreció una vertiente más práctica del arte, permitiendo clases de dibujo elemental a los artesanos. En todo el debate generado, el grabado comenzó a ser valorado y defendido en una doble vertiente, artística y didáctica. Así, a través

29. Manuel Ossorio y Bernard: Galería biográfica de artistas españoles del siglo XIX, Giner, Madrid, 1975, p. 480. Reproducción facsímil de la edición de 1868. 
de la literatura artística, el retrato y las instituciones culturales de la época, comienza a vislumbrarse un florecimiento en el estatus social de la figura del grabador que tendrá su reflejo en la imagen que muestran de sí mismo y de su profesión. 